\title{
Global land surface phenology trends from GIMMS database
}

\author{
Y. JULIEN* and J. A. SOBRINO \\ Global Change Unit, Department of Thermodynamics, University of Valencia, c/Dr. \\ Moliner, 50-46100 Burjassot, Spain
}

(Received 21 November 2007; final version received 27 June 2008)

\begin{abstract}
A double logistic function has been used to describe global inventory mapping and monitoring studies (GIMMS) normalized difference vegetation index (NDVI) yearly evolution for the 1981 to 2003 period, in order to estimate land surface phenology parameter. A principal component analysis on the resulting time series indicates that the first components explain 36, 53 and $37 \%$ of the variance for the start, end and length of growing season, respectively, and shows generally good spatial homogeneity. Mann-Kendall trend tests have been carried out, and trends were estimated by linear regression. Maps of these trends show a global advance in spring dates of 0.38 days per year, a global delay in autumn dates of 0.45 days per year and a global increase of 0.8 days per year in the growing seasons validated by comparison with previous works. Correlations between retrieved phenological parameters and climate indices generally showed a good spatial coherence.
\end{abstract}

\section{Introduction}

Vegetation phenology is the study of recurring patterns of vegetation growth and development, as well as their connection to climate (White et al. 1997). It has become of increasing interest to the scientific community with the focus on global change research, since an accurate detection of phenological phases allows estimation of the spatiotemporal dynamics of carbon and water cycles (Schwartz 1992). Numerous ground phenological studies have been conducted, but the difficulty of unifying data records over plant species and phenological events (Ahas et al. 2002, Schwartz et al. 2006) undermines the use of these data records for vegetation change detection at global scale. With the increasing length of the available satellite data record, NASA has singled out land surface phenology as a supplementary tool for vegetation monitoring (Friedl et al. 2006). Land surface phenology is defined as the seasonal pattern of variation in vegetated land surfaces observed from remote sensing (White and Nemani 2006) and presents the advantage of a global coverage, which dispenses tedious fieldwork that is unachievable at global scale. However, remotely sensed data also present drawbacks, such as the influence of the atmosphere (cloud contamination, atmospheric absorption), spatial averaging over species due to pixel size and temporal frequency of data acquisition (from 15 minutes to more than 1 week, depending on the satellite orbits).

Land surface phenology is usually addressed through temporal monitoring of the normalized difference vegetation index (NDVI) (Rouse et al. 1973) time series, available since the launch of the first Earth observation satellites. The NDVI is

\footnotetext{
*Corresponding author. Email: yves.julien@uv.es
} 
calculated as the normalized difference between near-infrared and red bands, and quantifies the photosynthetic capacity of plant canopies, thus indicating the amount of vegetation present in one place. Monitoring NDVI time series provides information on phenological phases, such as onset (green wave) or dormancy (brown wave) of vegetation where these phases exist.

Various methods have been developed for retrieving phenological dates from NDVI data. The first method (method 1) consists of the prescription of thresholds (Lloyd 1990, Fischer 1994, Reed et al. 1994, Myneni et al. 1997, Zhou et al. 2001, Shabanov et al. 2002, Zhou et al. 2003, Chen et al. 2005) corresponding to a given percentage of NDVI amplitude, fixed arbitrarily or from additional pixel information. This method, although easy to implement, suffers a major drawback, which is the noise present in the temporal NDVI series, caused both by atmospheric and sensor variations. The second method (method 2) consists of the identification of phenological dates based on the mid-point in the annual range of NDVI values (White et al. 1997, Delbart et al. 2005). This method suffers from the same drawbacks as the first one. The third method (method 3) is based on the rate of change in NDVI values to estimate the transition dates, and is also influenced by atmospheric conditions (Moulin et al. 1997, Tateishi and Ebata 2004, Piao et al. 2006). The fourth method (method 4) allows the estimation of transition dates via spectral or harmonic analysis (Moody and Johnson 2001, Stöckli and Vidale 2004, Julien et al. 2006), which diminishes the influence of cloud-contaminated NDVI values on the transition dates. Another method (method 5) consists of fitting NDVI temporal series to a given function, which provides transition dates, among other parameters (Badhwar 1984, Tucker et al. 2001, Jonsson and Eklundh 2002, Beck et al. 2006). This method also allows the screening of cloud-contaminated values during the fitting procedure, by removing all negative outliers from the time series, since cloud or snow contamination tend to diminish NDVI values. The last method (method 6) consists of fitting NDVI time series to accumulated growing degree-days (de Beurs and Henebry 2005a,b). This method needs additional information (climate data) to estimate degree-days. The accuracy of all these methods rely on the compositing period used when building the NDVI dataset used for phenology retrieval: a longer compositing period lowers the probability of cloud-contaminated data, but also diminishes the time resolution at which the growing cycle of a given land cover is observed, which is problematic for some biomes (artic tundra and vegetation in arid and semi-arid areas; Holben 1986).

These methods have been used for three purposes: studying temporal variations of phenological dates (see, for example, Zhang et al. 2004, Sakamoto et al. 2005), realtime monitoring and short-term forecasting of land surface phenology (White and Nemani 2006) and retrieving trends for phenological dates (see, for example, Myneni et al. 1997, Tucker et al. 2001, Zhou et al. 2001). Since the work presented in this paper focuses on retrieved trends for phenology, studies dedicated to trend estimation only are reviewed here. Myneni et al. (1997) carried out the first global land surface phenology study using method 1, finding a general advance in spring dates of 8 days between 1981 and 1991, and an increase in growing season (defined as photosynthetic active period) around 12 days over the same period. Several works have been carried out since (Tucker et al. 2001, Zhou et al. 2001, Stöckli and Vidale 2004, Chen et al. 2005, Delbart et al. 2005, Piao et al. 2006), which all found an advance of the spring date, from 0.25 to 0.8 days per year during periods between 1981 and 2004, over areas ranging from national to global scale. Only one study 
(Delbart et al. 2005) found a delay in spring occurrence of 0.3 days per year over boreal areas between 1993 and 2004. All the mentioned NDVI studies also evidenced a lengthening of the growing season, ranging from 0.05 to 1.01 days per year. Other studies have dealt with the determination of land surface phenology over smaller areas (see, for example, Osborne et al. 2000, Tao et al. 2006, Høgda et al. 2007), generally pointing at an advance in spring phases and a delay in autumn phases, resulting in a lengthening of the growing season, similar to the global studies reviewed above. As can be observed, few land surface phenology studies (Myneni et al. 1997) have been carried out at global scale, the other studies being centred on the northern hemisphere, at local to continental scale. Moreover, phenological results have been averaged over large areas before trend retrieval, with local trends being dissolved into the main trend. Finally, studies with the largest geographical extension have been conducted on datasets suffering from various flaws, such as orbital drift and volcanic aerosol contamination after Mount Pinatubo's eruption in 1991.

In addition to remotely sensed land surface phenology, numerous studies have been carried out to compile phenological data from various ground stations. These phenological studies have the advantage of the time extent (some datasets begin before 1950) to compare with the earlier Earth observation satellite images (1980). Regional phenological studies (Menzel and Fabian 1999, Beaubien and Freeland 2000, Ahas et al. 2002, Chmielewski and Rötzer 2002, Wolfe et al. 2005, Schwartz et al. 2006) have been concentrated on the northern hemisphere and restricted to determining trends in spring phases, evidencing generally an earlier spring occurrence (defined as budding, leafing or flowering dates) ranging from 0.125 to 0.8 days per year, for periods ranging from 1951 to 2002. Only one study (Ahas et al. 2002) found a later spring occurrence ( 0.218 days per year) over eastern Europe during this same period.

To end this review of retrieved trends in global phenology, some authors (Keeling et al. 1996, Carter 1998, Schwartz and Chen 2002, Linderholm et al. 2008) have also used climate records to estimate phenological phases, the methodology being based on temperature changes over the study period, or on degree-day models. Those studies have been carried out at regional to global scale between 1890 and 2000, evidencing an earlier occurrence of spring (from 0.075 to 0.171 days per year), and a later occurrence of autumn (from 0.026 to 0.114 days per year), resulting in a lengthening of the growing-season period (from 0.132 to 0.285 days per year). More information on the NDVI, ground phenology and climate studies is summarized later in table 1 .

Trends in phenological phases are usually estimated using linear regression over the study periods, though the use of the Mann-Kendall test (Hirsch and Slack 1984, de Beurs and Henebry 2005a,b), which allows a rigorous determination of trend presence, overcoming the usually neglected linear regression basic assumptions.

Among all the studies reviewed above, very few have been dedicated to the whole globe, and most of them have focused on the northern hemisphere. The aim of the study presented here is to retrieve local land surface phenology trends for the whole globe. The study has been conducted on global inventory mapping and monitory studies (GIMMS) NDVI retrieved between July 1981 and December 2003. These data are fitted yearly to a double logistic function, which allows the retrieval of spring and autumn dates, along with four other parameters for each one of the 22 years of data. A principal component analysis (PCA) is carried out on the time series of phenological phases to assess procedure stability. Spring and autumn date time 
series are then tested for trends, and those trends estimated by linear regression. Finally, those trends are compared with climate indicators.

\section{Data}

The GIMMS dataset (Pinzon 2002, Pinzon et al. 2004, Tucker et al. 2005) compiles NDVI images acquired by the advanced very high resolution radiometer (AVHRR) sensor aboard National Oceanic and Atmospheric Administration (NOAA) satellites. The database is composed of quasi 15 day composites from July 1981 to December 2003. The composite images are obtained by the maximum value compositing (MVC) technique (Holben 1986), which minimizes the influences of atmospheric aerosols and clouds. More than 22 years of data have been covered by five different satellites: NOAA-7, 9, 11, 14 and 16. The NDVI images are obtained from AVHRR channel 1 and 2 images, which correspond respectively to red $(0.58$ to $0.68 \mu \mathrm{m})$ and infra-red wavelengths $(0.73$ to $1.1 \mu \mathrm{m})$.

This dataset, in spite of its limitation to NDVI data (no other channel information is available), presents several improvements regarding its predecessor, the Pathfinder AVHRR Land (PAL) dataset (Smith et al. 1997). The first improvement consists of a better data process, including navigation, sensor calibration and atmospheric correction for stratospheric aerosols. Another main improvement regards the correction of NOAA's orbital drift (Price 1991), through the empirical mode decomposition (EMD) technique (Pinzon et al. 2004). The work presented here has been carried out using GIMMS NDVI data only.

Validity of the GIMMS dataset has been discussed in previous studies (Zhou et al. 2001, Tucker et al. 2005), so it is not assessed here. However, the GIMMS group itself points out two problems with the data: the volcanic eruption of Mount Pinatubo in mid-1991, which decreased NDVI values, particularly affecting tropical regions; and the corrections made for extremely high solar zenith angles during winter for areas north of $65^{\circ} \mathrm{N}$. As a consequence, these results have to be treated with caution. Additionally, the GIMMS group advises not to draw local conclusions from the data, since its NDVI present generalized patterns. For this study, the whole dataset has been used, with the exception of the data between July and December 1981 for the northern hemisphere and between July and December 2003 for the southern hemisphere. This selection had to be made because the estimation of spring and autumn dates needs complete years of information. GIMMS data were used indiscriminately of their flag attribute, in order to dispose of the maximum number of pixels, to cover the whole globe. This does not affect the results, since the GIMMS pixels issued from a model to compensate for the lack of data (mainly in high latitudes and mountain areas) have a constant value, which means that no trend can be retrieved over the corresponding areas. Therefore, the eventual absence of trend in those regions would be due to the characteristics of the database, and not to phenological stability.

\section{Methodology}

Stöckli and Vidale (2004) have singled out three basic assumptions regarding land surface phenology retrieval. These assumptions are that:

- vegetation phenology follows a repetitive seasonal cycle (Moulin et al. 1997) and NDVI values vary smoothly with time (Sellers et al. 1996); 
- during summer, outliers in NDVI time series are the result of either cloud cover or atmospheric disturbances, both tending to decrease NDVI values (Holben 1986, Los 1998); and

- during winter, snow under or temporarily on the canopy may impose a negative bias on the NDVI signal, since snow has a high visible reflectance and a low near-infrared reflectance.

We must add to the second assumption that outliers in NDVI time series are the result of either cloud cover or atmospheric disturbances also in winter. Therefore, outliers in the data tend to under-estimate NDVI values for the whole globe.

Considering this, Stöckli and Vidale (2004) chose to apply a Fourier adjustment algorithm (Sellers et al. 1996, Los 1998). Nevertheless, Beck et al. (2006) managed to retrieve land surface phenology by fitting NDVI data to a double logistic function. This method is also the one chosen for this study. The reason for this choice is the ability of the double logistic function to describe plateaus in NDVI evolution, corresponding to vegetation dormancy or extended photosynthesis peak period. These plateaus would require many harmonics to be described adequately, which would be too time demanding for a global analysis on a pixel-by-pixel basis. The preference of method 5 over the three other methods is due to their sensitivity to the noise resulting from atmospheric conditions. This approach has been partially developed in Julien and Sobrino (2007), with the work presented here including a major improvement in trend identification using Mann-Kendall trend tests, corrected for temporal autocorrelation, as well as a detailed description of the procedure carried out to estimate phenological parameters.

To study yearly NDVI evolutions, GIMMS data has been artificially divided into 1 year intervals, starting on 1 January and ending on 31 December for the northern hemisphere and starting on 1 July and ending on 30 June for the southern hemisphere. This distinction has been made in order to describe vegetation with the same function (see equation(1)) for both hemispheres. These dates have been selected as boundaries for yearly evolution because they correspond to dormancy for most of the biomes. However, for biomes with peak chlorophyll activity at those boundary dates, another fitting function has been implemented (equation (2)). Both fitting functions are shown in figure 1 . The choice between those two fitting functions is made after a preliminary fit to the data, choosing the fitting function for which the root mean square (RMS) error is lower. NDVI yearly evolutions are thus fitted to the following double logistic function (Beck et al. 2006):

$\operatorname{NDVI}(t)=\mathrm{wNDVI}+(\mathrm{mNDVI}-\mathrm{wNDVI}) \times\left(\frac{1}{1+\mathrm{e}^{-\mathrm{mS}(t-S)}}+\frac{1}{1+\mathrm{e}^{\mathrm{mA}(t-A)}}-1\right)$,

where $\operatorname{NDVI}(t)$ is the remotely sensed NDVI evolution for a given year ( $t=0$ to 364 , in day of year), wNDVI is the winter NDVI value; mNDVI is the maximum NDVI value; $S$ is the increasing inflection point (spring date); $A$ is the decreasing inflection point (autumn date); $\mathrm{mS}$ is related to the rate of increase at the $S$ inflection point; and $\mathrm{mA}$ is related to the rate of decrease at the $A$ inflection point. All these parameters are retrieved iteratively on a pixel-by-pixel basis for each of the 22 years available from the GIMMS database, using the Levenberg-Marquardt technique (More 1977). Since GIMMS NDVI images are bi-weekly, acquisition dates for each composite have been set to the day corresponding to the middle of the compositing period. A preliminary fit is conducted in order to estimate the dormancy period as the period before the spring date and after the autumn date. During this period, all 


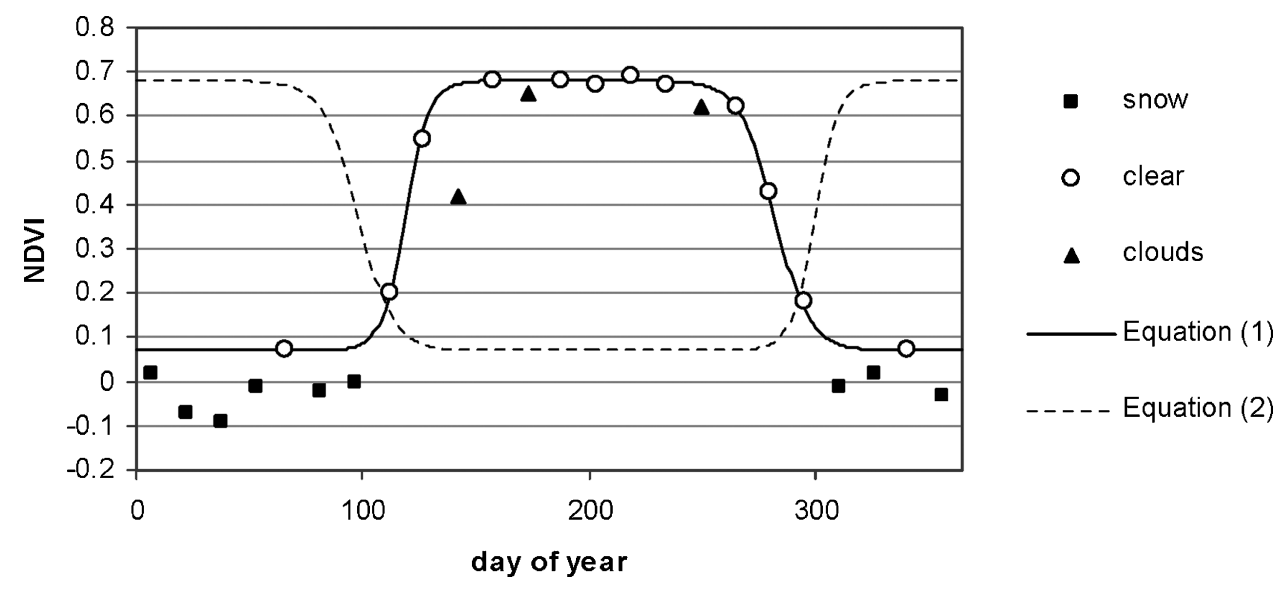

Figure 1. Shape of the fitting functions. Original data have been divided into three categories: snow contaminated (squares), clear (circles) and cloud contaminated (triangles). The fitting function (solid line) used for these data is equation(1), with the following parameters: $\mathrm{wNDVI}=0.07, \mathrm{mNDVI}=0.68, S=119, A=282, \mathrm{mS}=0.19$, and $\mathrm{mA}=0.13$. For information, the same data has been fitted from Julian day 181 to 365 and then 1 to 180 using equation(2) (dotted line). Outliers (squares and triangles) are rejected to obtain a smooth curve from which phenological parameters are retrieved.

eventual negative NDVI values are set to the highest positive value over the whole dormancy period.

Biomes with photosynthetic activity at boundary dates (usually in arid or semiarid areas) are fitted to the following function:

$\operatorname{NDVI}(t)=\mathrm{mNDVI}-(\mathrm{mNDVI}-\mathrm{wNDVI}) \times\left(\frac{1}{1+\mathrm{e}^{-\mathrm{mS}(t-S)}}+\frac{1}{1+\mathrm{e}^{\mathrm{mA}(t-A)}}-1\right),(2)$

where all parameters are the same as for equation (1). The preliminary fit carried out over NDVI yearly data also helps to choose between equations (1) and (2), selecting the equation closest to the data.

For those biomes with low NDVI amplitude variation throughout the year (lower than 0.1 NDVI unit), no fitting procedure is carried out and the mNDVI and wNDVI are fixed to the mean value of the NDVI over the considered year. These biomes correspond to arid or frozen areas, as well as cloud-free evergreen vegetation. Equation (1) describes most of the world biomes accurately, since it includes a period of photosynthetic peak activity, with NDVI values close to the mNDVI, and a period of lower photosynthetic activity, for which NDVI values are close to the wNDVI. This lower photosynthetic activity period can correspond to vegetation dormancy (higher latitudes and deciduous species), to higher rate of leaf fall in evergreen forests (rainforests, see Huete et al. (2006)), to snow under or temporarily on the canopy of evergreen forests at higher latitudes, or to vegetation under enduring cloud cover.

The fitting functions presented above (equations (1) and (2)) do not correctly describe vegetation with more than one peak chlorophyllic activity. For example, in some tropical and semi-arid areas, the vegetation can present a bi-modal NDVI yearly curve. This bi-modal NDVI pattern corresponds to areas with two growing seasons during the year such as agricultural areas under two plantation cycles per 
year, and biomes where growth is constrained by both cold (winter) and drought (summer). In that case, one of the low NDVI period would be considered as a dormancy period while the other is considered as a plateau with cloud-contaminated values. Nevertheless, the retrieved parameters are correct, even if half the information is missing. An additional consequence of this fact can be a higher temporal variability of spring and autumn dates for those areas. However, only a low percentile $(2.5 \%)$ of the analysed pixels corresponds to this type of vegetation, those pixels being located mainly in tropical areas (see figure 2), where enduring cloud cover is frequent, and thus undermines the fitting procedure. This is the reason why no third function has been added to the first two, the costs in terms of calculation time being too high.

The fitting procedure is carried out iteratively on a pixel-by-pixel basis for each of the 22 years available from the GIMMS database, using the Levenberg-Marquardt technique (More 1977). First, if yearly NDVI time series are below zero, or with an amplitude lower than 0.1 , corresponding to frozen or stable areas, respectively, the pixel is flagged as such, and no fitting procedure is carried out. Otherwise, as mentioned above, a preliminary fit is conducted in order to choose between equations (1) and (2). From this preliminary fit, the dormancy period is estimated as the period before the spring date and after the autumn date. During this period, all eventual negative NDVI values are set to the highest positive value over the whole dormancy period. A weighted fit is then carried out iteratively to the selected function (equations(1) or (2)): all NDVI values below the fitting function are considered to be cloud-contaminated values, therefore a lower weight is attributed to them at each iteration. The procedure is stopped when the total difference between the weighted data and the fitting function is lower than 0.05 NDVI units. Finally, the fitting parameters are tested for consistency (wNDVI $\geqslant 0, \quad \mathrm{mNDVI} \leqslant 1$, wNDVI $\leqslant \mathrm{mNDVI}, \quad 0 \leqslant S$ and $A \leqslant 365, \quad S \leqslant A$ for equation(1) and $A \leqslant S$ for equation(2)). If these last tests are successful, the pixel is flagged as such, else it is flagged as unsuccessful. Additionally, when the difference between the NDVI and the fitting curve is higher than 0.05 NDVI units for any date where no cloud or snow has been detected, the fitting procedure for the corresponding pixel is flagged as unsuccessful. Therefore, one flag image is obtained for each year of data, indicating
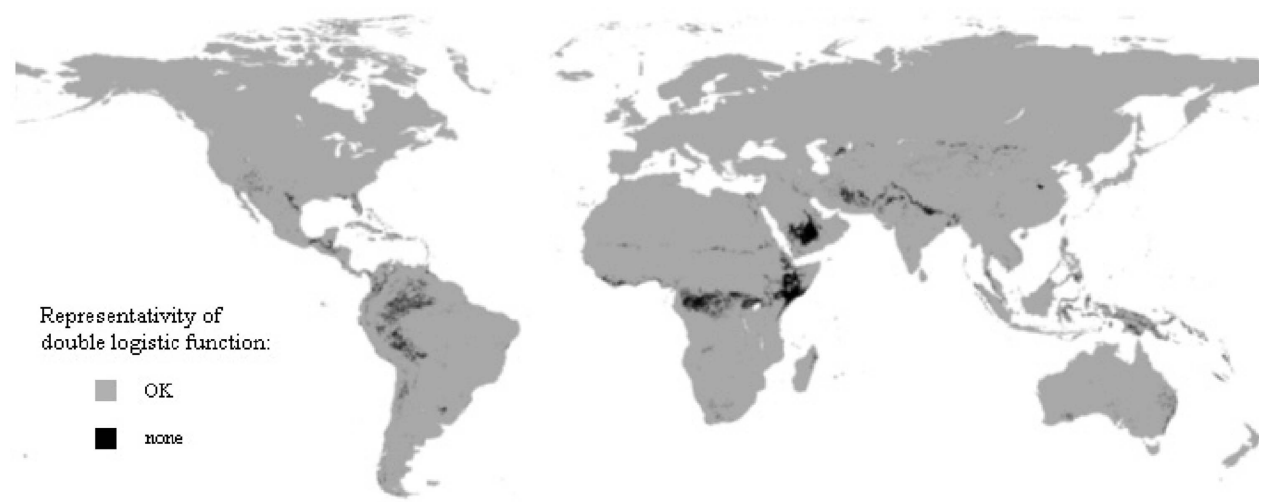

Figure 2. Global representativity of the double logistic function. This image corresponds to significant correlation $(p<0.05)$ of the average NDVI yearly cycle (computed over the whole GIMMS database) with a double logistic function. Grey corresponds to significant correlation and black to the absence of significant correlation at 95\% confidence level. 
the quality of the fitting procedure. A schematic view of this fitting procedure can be seen in figure 3. Finally, growing-season length is estimated as the difference between the autumn and spring dates.

In the case of standard biomes (one chlorophyll peak activity per year), the main source of inaccuracy of this procedure is due to the composite nature of the data. A simulation has been conducted in order to estimate the accuracy in determining the spring and autumn dates: a date of acquisition has been attributed randomly within each 15 day compositing period of a standard yearly NDVI profile, which simulates the error made when attributing acquisition date to the median day of the compositing period. The standard NDVI profile was presented in figure 1. A total of 100000 different simulations have been calculated, leading to standard deviations of \pm 5.5 days uncertainty for spring and autumn dates and \pm 7.8 days for growingseason length.

Another source of inaccuracy of this procedure resides in the determination of the winter NDVI value. If the highest positive NDVI value over the whole dormancy

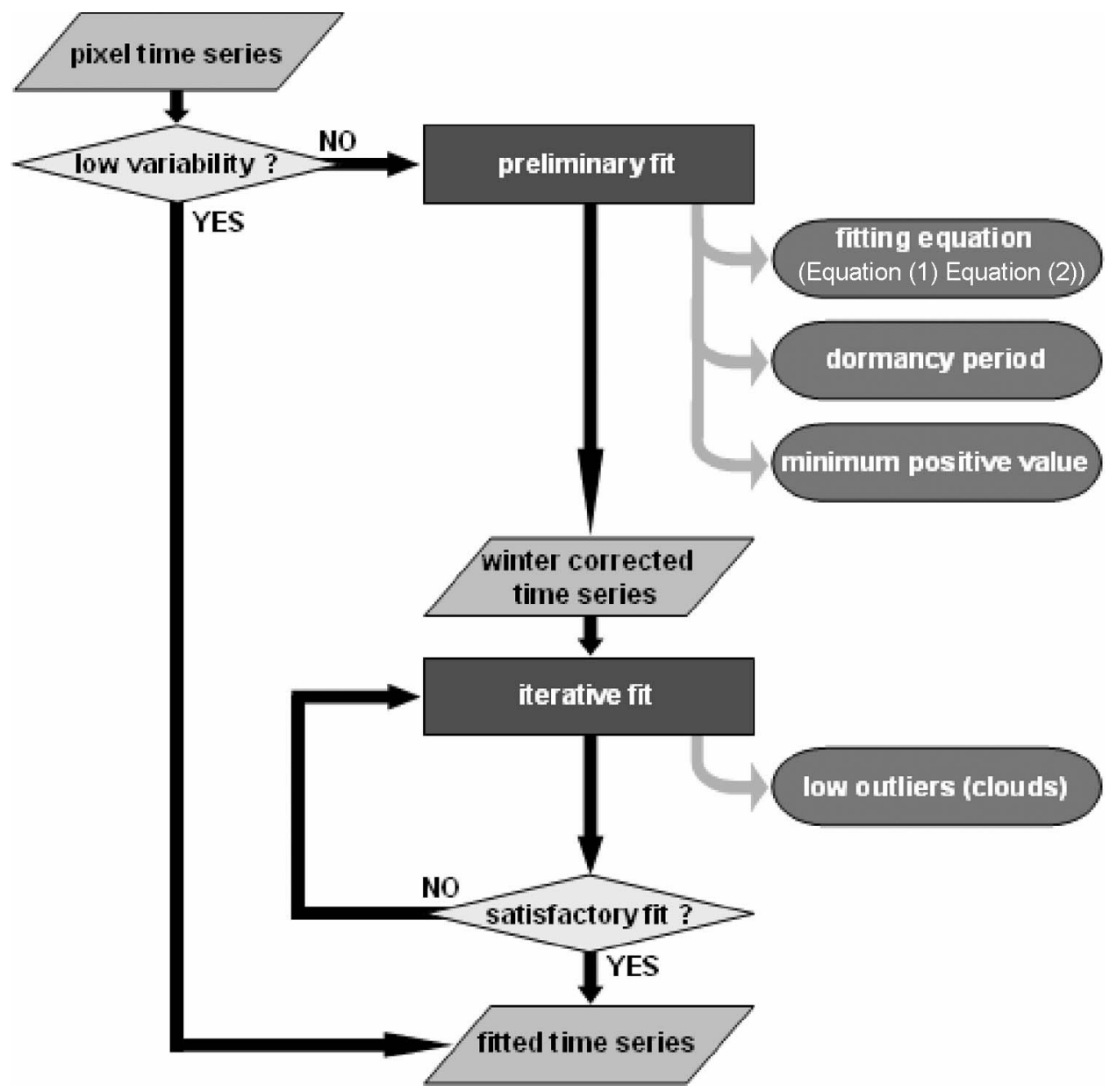

Figure 3. Schematic view of the fitting procedure, leading to the determination of phenological phases (spring and autumn dates and growing-season length) for each pixel and each year of GIMMS data. 
period corresponds to a contaminated value (by cloud or snow presence), then all retrieved parameters suffer from this contamination. For example, an error of 0.1 NDVI units in winter NDVI value leads to errors in retrieved spring and autumn dates of the same magnitude as the uncertainty due to compositing. This means that in cases of cloud contamination, for example, during the whole low-activity period, as may be the case in tropical areas, phenological dates may show higher variability.

Once the time series of spring, autumn and growing-season length have been retrieved, a statistical analysis was conducted. First, in order to determine if trends were present in the time series, a Mann-Kendall (Hirsch and Slack 1984) test is performed. The Mann-Kendall statistic for a monotone trend in a time series $\left\{Z_{k}\right.$, $k=1,2, \ldots, n\}$ of data is defined as:

$$
T=\sum_{j<i} \operatorname{sgn}\left(Z_{i}-Z_{j}\right)
$$

where

$$
\operatorname{sgn}(x)=\left\{\begin{array}{ccc}
1, & \text { if } & x>0 \\
0, & \text { if } & x=0 \\
-1, & \text { if } & x<0
\end{array}\right.
$$

If the values of $Z_{1}, Z_{2}, \ldots, Z_{n}$ are randomly ordered, this statistic test has expectation zero and variance:

$$
\operatorname{Var}(T)=\left\{n(n-1)(2 n+5)-\sum_{j=1}^{p} t_{j}\left(t_{j}-1\right)\left(2 t_{j}+5\right)\right\} / 18,
$$

where $p$ is the number of tied groups in the dataset and $t_{j}$ is the number of data points in the $j$ th tied group. Furthermore, if $n$ is large $(n>10), T$ is approximately normal (Kendall 1975).

This test has been carried out only for pixels with a successful fitting procedure for at least 15 out of the 22 years of data $(15 \leqslant n \leqslant 22)$, in order to consider $T$ as a normal distribution. Then, confidence intervals at $90 \%$ were estimated to reject the null trend hypothesis. This test indicates whether a trend exists for the considered pixel, giving only information on the sign of this trend. However, to compare our results with previous work, numerical trend values have to be retrieved. We have therefore chosen to estimate trends by simple linear regression for those pixels passing the Mann-Kendall trend tests at 90\% confidence level $(p<0.1, \alpha=0.9)$.

A PCA has been carried out on the spring, autumn and growing-season length time series (22 years), in order to determine the stability of the approach. For this PCA analysis, only pixels with retrieved phenology have been considered, leaving out pixels corresponding to sea or stable areas. Therefore, the input matrix of the PCA is a $2492954 \times 22$ matrix, corresponding to the number of pixels showing seasonal changes and the number of years covered in the GIMMS database. This PCA has been conducted on both variance-covariance and correlation matrices, leading to similar results. Thus, only results of the PCA conducted on the correlation matrices are presented here.

In order to validate the retrieved time series of start, end and length of growing season, correlations have been calculated with time series of climate indices, such as the southern oscillation index (SOI) (http://www.bom.gov.au/climate/current/ 
soihtm1.shtml), North Atlantic oscillation (NAO) (http://www.cpc.noaa.gov/ products/precip/CWlink/pna/nao.shtml) and Pacific decadal oscillation (PDO) (http://jizao.washington.edu/pdo/PDO.latest). The SOI corresponds to the Tahiti minus Darwin normalized pressure index, which measures whether the climate system is in the El Niño or La Niña state. One can observe that the SOI has a global influence on growing-season parameters, and is not restricted to its geographical area. This occurs as teleconnections as the atmosphere transmit anomalous heating in the tropics to large-scale convection and thus to anomalous winds in the atmosphere. The NAO index measures the large-scale alternation of atmospheric pressure between the North Atlantic regions of the sub-tropical high (near the Azores) and sub-polar low pressure (extending south and east of Greenland), which determines the strength and orientation of the poleward pressure gradient over the North Atlantic, and the mid-latitude westerlies in this area. The PDO (also called the interdecadal Pacific oscillation (IPO)) index is derived as the leading principal component of monthly Sea Surface Temperature (SST) anomalies in the North Pacific Ocean, poleward of $20^{\circ} \mathrm{N}$ latitude. The monthly mean global average SST anomalies are removed to separate this pattern of variability from any 'global warming' signal that may be present. This index has been shown to be a significant source of decadal climate variation throughout the South Pacific and Australia, and also the North Pacific (Salinger 2005). Those global indices were retrieved as monthly means, and have been averaged yearly, from 1 January to 31 December for the northern hemisphere, and from 1 July to 30 June for the southern hemisphere. Pearson correlations were calculated between these series of annual climate indices and time series of growing-season start, end and length for each pixel and tested for statistical significance at $95 \%$ confidence level $(p<0.05, \alpha=0.95)$.

\section{Results}

The procedure presented above allows for retrieving yearly spring and autumn dates, which give an estimation of growing-season length for the 22 years of data. The resulting time series of growing-season parameters were analysed by PCA as described in $\S 3$. For spring images, the first component explains $36 \%$ of the variance, with the remaining variance being distributed homogeneously on the other components. For autumn images, the first component explains 53\% of the variance, with the remaining variance also being distributed homogeneously on the other components. Finally, for growing-season images, the first component explains $37 \%$ of the variance, the remaining variance being also distributed homogeneously on the other components. The variance explained by the first component is quite low. This is due to the yearly variability of phenological phases, as well as to local instability of the procedure (due to cloud or snow presence). Spatial heterogeneity can be observed in PCA first components for all parameters locally around the Equator (not shown). This is explained by the fact that, along the Equator, similar ecosystems are fitted differently, on the northern side using data from 1 January to 31 December and on the southern side using data from 1 July to 30 June (starting the previous year). This heterogeneity is reinforced by the enduring cloud cover during part of the year for the affected regions (Amazonia, central Africa), but also in the Indian subcontinent. This is due to the fact that the fitting procedure interprets the enduring cloud cover as a dormancy period (consistent with Huete et al. (2006)), which can be pixel dependent, leading to local spatial heterogeneity. This spatial variability is reinforced by the possible errors in the wNDVI parameter that are also due to the enduring 
cloud cover in these areas, which propagate in the spring and autumn dates, as stated above.

In order to estimate the validity of the retrieved phenological time series, an analysis of the flag time series has to be conducted. Figure 4 shows the number of years for which each pixel has been flagged as $(a)$ frozen, $(b)$ stable, $(c)$ unsuccessful or $(d)$ successful during the 22 years of the study. Figure $4(a)$ shows that the areas frozen throughout the year are located near the North Pole, consisting mainly of Greenland. In addition, a few areas are labelled as frozen, corresponding to inland water, which are not flagged as water within the GIMMS database. Since these areas do not correspond to land vegetation, this has no influence on the study. Regarding stable pixels, figure $4(b)$ shows that arid areas are labelled as stable (Sahara, Atacama, Namib and Taklimakan Deserts), as well as high mountains (Chilean Andes, Himalaya). On the other hand, many other areas are labelled only temporarily as stable, and correspond to rainforests (central America, Amazonia, Equator and southern Asia) or to semi-arid areas (part of the Arabic peninsula, central Australia, southern Spain, south western USA). Temporary presence of clouds (for the first group of areas), or temporary presence of vegetation (for the second group) explains these changes from year to year, as evidenced by visual inspection of the time series (not shown). Figure 4(c) shows pixels with errors in the fitting procedure, corresponding to a fitting function that is inadequate with input time series (see above). Pixels with unsuccessful fitting are located around the Equator and in enduring cloud cover areas (Amazonia, South Asia, and Central Africa), corresponding to the areas with spatial heterogeneity in the PCA, but also semi-arid areas, like Australia, Sahel or Mexico. Finally, figure 4(d) shows the pixels with successful fitting, which are logically complementary to the three previous flag images (figures 4(a) to $(c)$ ). The areas with the lowest successful fit are thus located around the Equator, in Amazonia, in Southern Asia and in Australia. Therefore,

(a)

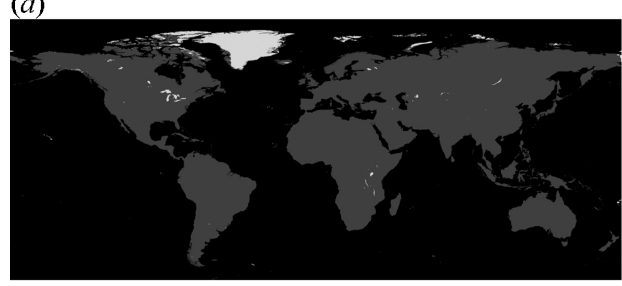

(c)

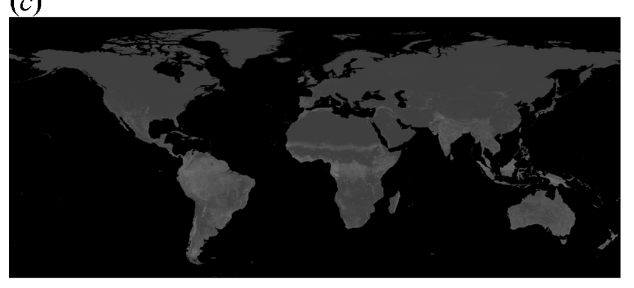

(b)

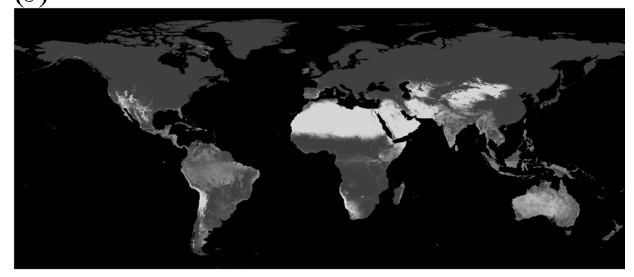

(d)

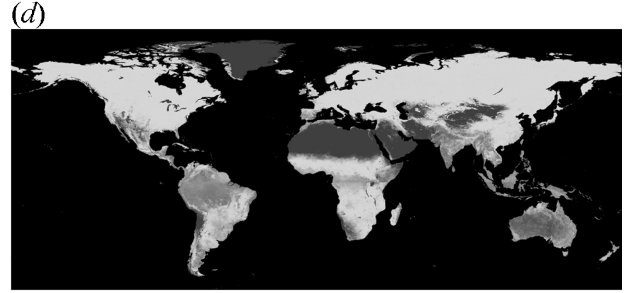

$\begin{array}{lllllllllllllllllllllllll}0 & 1 & 2 & 3 & 4 & 5 & 6 & 7 & 8 & 9 & 10 & 11 & 12 & 13 & 14 & 15 & 16 & 17 & 18 & 19 & 20 & 21 & 22\end{array}$

Figure 4. Accumulated flags of the fitting procedure for the 22 years of the study: $(a)$ frozen, (b) stable, (c) unsuccessful and (d) successful. Areas flagged as frozen correspond mostly to Greenland and inland water. Areas flagged as stable include deserts and rainforests. Areas flagged as unsuccessful correspond to highly variable areas, whether due to natural phenomena or noisy data. Results for grey areas in figure $4(d)$ are to be treated with caution. 
results for these areas are to be treated with caution, since the observed variability is due to natural variability as well as outliers in the data.

Mann-Kendall trend tests have been carried out for each pixel time series, and trends have been determined by linear regression for those pixels for which the notrend hypothesis could be rejected at $90 \%$ confidence level. The results are presented in figure 5 for spring, autumn and growing-season time series. Retrieved spring dates (figure $5(a)$ ) have seen an advance on average of 0.38 days per year over the whole globe (the average has been calculated over all the pixels for which a significant trend was retrieved), the image being scaled between advances of 3.6 days per year and delays of 2.8 days per year. Areas seeing the highest advances in spring dates are located in western Europe, Sahel and patches of eastern Asia, while areas seeing the highest delays are located in central North America, south eastern South America, east sub-equatorial Africa and patches of eastern Asia. For autumn dates (figure $5(b)$ ), an average delay of 0.45 days per year can be evidenced, with the image being scaled between advances of 4.8 days per year and delays of 5.7 days per year. Areas seeing the highest delays in autumn dates are located in sub-Saharan Africa and south eastern South America, while areas seeing the highest advances are located in patches of western Europe, North America, eastern Asia and around the Caspian Sea. Finally, for growing-season length (figure 5(c)), an average increase of 0.8 days per year can be evidenced at global scale, the image being scaled between decreases of 3.5 days per year and increases of 5.1 days per year. Areas seeing the highest increases are located in southernmost South America, southern Scandinavia, westernmost USA and patches of central Asia, while areas seeing the highest decreases are located at northernmost latitudes, in central USA, southern Amazonia, South Africa and patches of eastern Asia. One can observe that the areas mentioned in the previous paragraphs as unreliable, due to unsuccessful fit or high spatial heterogeneity, do not exhibit statistically significant trends, although those trends might exist. This lack of statistically significant trends is purely due to the fitting procedure. Another observation is that some of the trends present extreme values, which would correspond to changes in land surface phenology of 2 to 4 months during the 22 years of the study. These extreme values could be explained by abrupt changes in NDVI evolutions (due to deforestation or cloud cover), for example in southern Amazonia.

\section{Discussion}

In order to compare the trends presented above with previous studies, averages have been calculated for comparable areas and time extents when possible, and are presented in table 1. Geographic locations have been downscaled to country sizes, and study start years have been extended back to 1982 where previous years are indicated. Previous NDVI studies are easier to compare with the results presented above since land surface phenology phases were also retrieved from AVHRR data, although from different datasets, while climate $(\mathrm{C})$ and phenological $(\mathrm{P})$ studies were carried out from totally different data. Nevertheless, those results do provide an estimation of the representativity of land surface phenology as to ground station based phenology. In table 1, the results for the method presented here have been obtained by spatial averaging over pixels within the corresponding countries with successful fitting. This means that, in spite of similar geographical coverage, the start, end and length of growing season can be estimated from smaller areas. For NDVI studies, spring date trends are generally in agreement with previous ones 
(a)
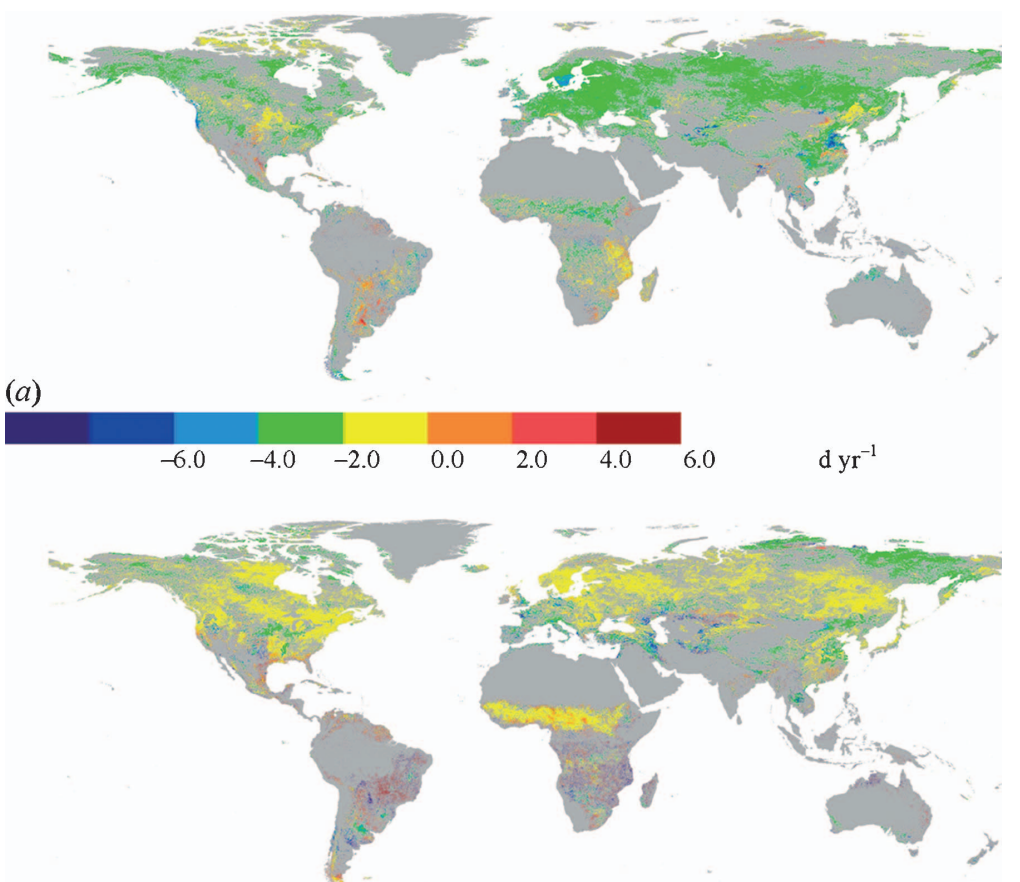

(b)

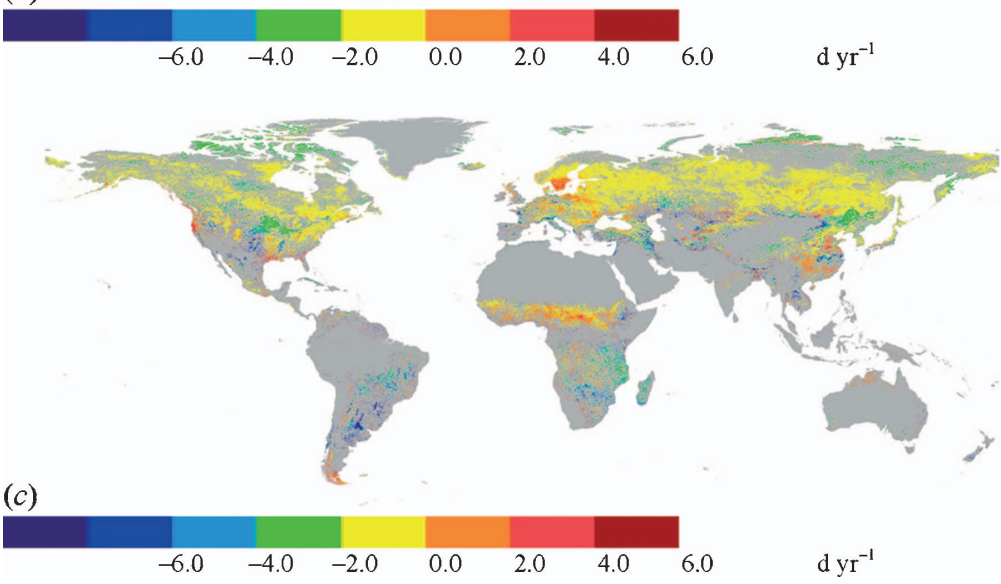

Figure 5. Trends (in days per year) in: (a) spring dates, $(b)$ autumn dates and (c) growingseason length for pixels exhibiting trends at 90\% confidence level between 1981 and 2003, as identified by Mann-Kendall trend tests carried out on time series of phenological parameters retrieved by fitting yearly NDVI evolution to a double logistic function. Retrieved trends are generally towards earlier onset of spring and later occurrence of autumn, resulting in an increased growing-season length.

(Tucker et al. 2001, Zhou et al. 2001, Stöckli and Vidale 2004, Delbart et al. 2006), with the retrieved values being comparable. For growing-season length, only one estimation (Stöckli and Vidale 2004) agrees. The differences between our results and previous studies are probably due to the way the averages are obtained: in our case, only pixels showing phenology have been considered, increasing the retrieved trends since stable areas (therefore with smaller trends) have not been included in the 
average. For studies from phenological records, the results for spring date trends compare well with the ones obtained by the methodology described above in the cases of global studies (Ahas et al. 2002, Schwartz et al. 2006), probably due to the high number of stations used for these studies. Trends in phenology retrieved from climate data compare badly with the results of this study.

Figure 6 shows the pixels for which correlations with climate indices were significant at $95 \%$ confidence level $(p<0.05)$, in black for negative correlations, and in white for positive correlations. Large spatial patterns of statistically significant correlations can be observed for spring over western and eastern Europe, southern North America, and more locally over the rest of the globe (figure 6(a)). Regarding correlation with autumn time series (figure $6(d)$ ), positive correlations are located at northernmost and southernmost latitudes, while negative correlations are mainly located in western Europe and Amazonia. Regarding correlation with growingseason length time series (figure $6(g)$ ), negative correlations are observable around the northern Atlantic Ocean, while positive correlations spread over the rest of the globe, with greater spatial homogeneity over eastern and western Russia. Spring and NAO time series show significant positive correlations mainly in the eastern north Atlantic Ocean (namely in Iceland and the Great Lakes area), while negative correlations can be observed in Lapland (figure 6(b)). Regarding autumn time series (figure6(e)), only eastern Europe shows a clear pattern of negative significant correlation with NAO index, while small patches of significant correlation can be observed locally all around the world. Regarding growing-season time series (figure 6(h)), significant negative correlations with NAO index are located in the Great Lakes region, in Amazonia and in southern Africa. Small patches of significant positive correlation are visible over the whole globe, with a larger extent

SOI

(a)

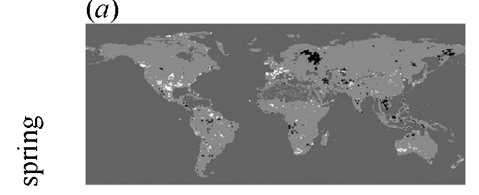

(d)

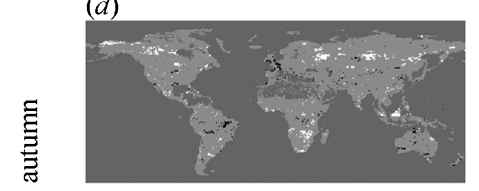

(g)

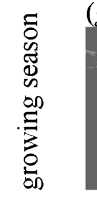

NAO

(b)

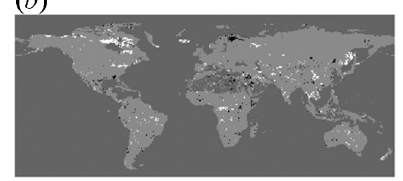

(e)

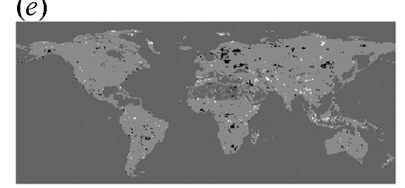

(h)

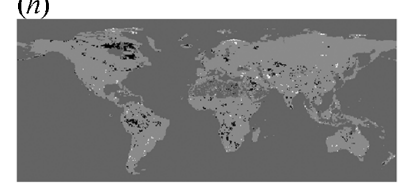

PDO

(c)

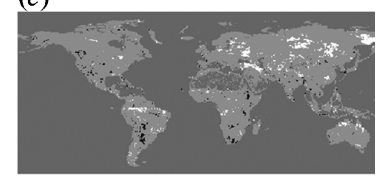

(f)

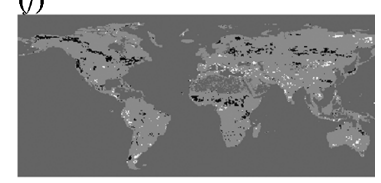

(i)

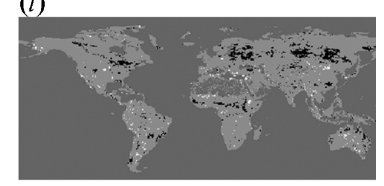

significant positive correlation

- insignificant correlation

significant negative correlation

Figure 6. Correlation between spring, autumn, growing season and SOI, NAO, PDO indices between 1981 and 2003. White indicates statistically significant positive correlation at $95 \%$ confidence level, black indicates statistically significant negative correlation at $95 \%$ confidence level, while grey indicates statistically insignificant correlation at $95 \%$ confidence level. Large contiguous patches of significant correlation show the validity of the approach. 
Table 1. Comparison of the results of this study (grey) with previous ones. 'Type' indicates on which kind of records the previous studies were carried out: 'PAL' for satellite images from the PAL database, 'GIMMS' for satellite images from the GIMMS database, ' $4 \mathrm{~km}$ ' for satellite images from a $4 \mathrm{~km}$ AVHRR dataset, 'VGT' for satellite images from SPOT-VEGETATION instrument, 'P' for phenological ground stations and 'C' for climate data. 'Start', 'End' and 'Length' refer respectively to growing-season start, end and length in days per year. An ' $\mathrm{X}$ ' indicates that the corresponding parameter has not been estimated. Values in bold indicate statistically significant values at $95 \%$ confidence level. The results of this study agree with many previous works, especially with the ones retrieved from satellite data and large phenological records.

\begin{tabular}{|c|c|c|c|c|c|c|c|c|c|}
\hline \multicolumn{7}{|l|}{ Previous studies } & \multicolumn{3}{|c|}{ This study } \\
\hline Reference & Type & Period & Location & Start & End & Length & Start & End & Length \\
\hline Myneni et al. $(1997)^{\mathrm{A}, 1}$ & PAL & 1981-1991 & Global & -0.727 & $\mathrm{X}$ & 1.09 & -0.295 & 0.053 & 0.554 \\
\hline Tucker et al. $(2001)^{\mathrm{A}, 5}$ & $4 \mathrm{~km}$ & 1982-1991 & $45^{\circ} \mathrm{N}-75^{\circ} \mathrm{N}$ & -0.6 & $X$ & 0.4 & -0.648 & 0.247 & 0.893 \\
\hline Tucker et al. $(2001)^{\mathrm{A}, 5}$ & $4 \mathrm{~km}$ & 1992-1999 & $45^{\circ} \mathrm{N}-75^{\circ} \mathrm{N}$ & -0.25 & $X$ & 0.05 & -0.318 & 0.512 & 0.816 \\
\hline Zhou et al. $(2001)^{\mathrm{A}, 1}$ & GIMMS & 1981-1999 & Eurasia & -0.368 & $X$ & 0.947 & -0.293 & 0.156 & 0.462 \\
\hline Zhou et al. $(2001)^{\mathrm{A}, 1}$ & GIMMS & 1981-1999 & N America & -0.421 & $\mathrm{X}$ & 0.631 & -0.121 & 0.363 & 0.461 \\
\hline Stöckli and Vidale $(2004)^{\mathrm{B}, 4}$ & PAL & $1982-2000$ & Europe & -0.568 & $X$ & 1.01 & -0.628 & 0.193 & 0.883 \\
\hline Chen et al. $(2005)^{\mathrm{B}, 1}$ & PAL & $1982-1993$ & China & $\mathrm{X}$ & $\mathrm{X}$ & 1.083 & -0.653 & -0.319 & 0.359 \\
\hline de Beurs and Henebry $(2005 b)^{\text {A, C, } 6}$ & PAL & 1985-1999 & N America & -0.62 & $\mathrm{X}$ & $\mathrm{X}$ & -0.245 & 0.28 & 0.491 \\
\hline de Beurs and Henebry (2005b) A, C, 6 & PAL & $1985-2000$ & Eurasia & -0.42 & $\mathrm{X}$ & $X$ & -0.214 & 0.149 & 0.4 \\
\hline Delbart et al. $(2005)^{\mathrm{B}, 2}$ & PAL-VGT & $1982-1991$ & Boreal & -0.8 & $\mathrm{X}$ & $\mathrm{X}$ & -0.578 & 0.342 & 0.92 \\
\hline Delbart et al. $(2005)^{\mathrm{B}, 2}$ & PAL-VGT & 1993-2004 & Boreal & 0.3 & $\mathrm{X}$ & $\mathrm{X}$ & -0.354 & 0.169 & 0.522 \\
\hline Piao et al. $(2006)^{\mathrm{B}, 3}$ & GIMMS & 1982-1999 & $\mathrm{N}$ China & -0.744 & 0.35 & 1.094 & -0.32 & 0.075 & 0.367 \\
\hline Menzel and Fabian (1999) ${ }^{\mathrm{B}, \mathrm{C}}$ & $\mathrm{P}$ & $1951-1996$ & Europe & -0.136 & 0.097 & 0.234 & -0.466 & 0.235 & 0.787 \\
\hline Beaubien and Freeland $(2000)^{\mathrm{B}}$ & $\mathrm{P}$ & $1987-1996$ & Canada & -0.8 & $\mathrm{X}$ & $\mathrm{X}$ & -0.572 & 0.017 & 0.585 \\
\hline Ahas et al. (2002) & $\mathrm{P}$ & $1951-1998$ & $\mathrm{C} \& \mathrm{~W}$ Europe & -0.583 & $\mathrm{X}$ & $\mathrm{X}$ & -0.702 & 0.275 & 1.064 \\
\hline Ahas et al. $(2002)^{\mathrm{B}}$ & $\mathrm{P}$ & 1951-1999 & E Europe & 0.218 & $\mathrm{X}$ & $X$ & -0.223 & 0.198 & 0.421 \\
\hline Chmielewski and Rötzer $(2002)^{\mathrm{A}}$ & $\mathrm{P}$ & 1969-1998 & Europe & -0.266 & $\mathrm{X}$ & $\mathrm{X}$ & -0.712 & 0.305 & 1.092 \\
\hline Wolfe et al. $(2005)^{\mathrm{B}}$ & $\mathrm{P}$ & $1965-2001$ & NE USA & -0.135 & X & $\mathrm{X}$ & -0.025 & 0.358 & 0.395 \\
\hline Schwartz et al. $(2006)^{\mathrm{B}}$ & $\mathrm{P}$ & 1955-2002 & $\mathrm{NH}$ & -0.125 & $\mathrm{X}$ & $\mathrm{X}$ & -0.189 & 0.143 & 0.407 \\
\hline Keeling et al. $(1996)^{\mathrm{A}}$ & $\mathrm{C}$ & 1964-1992 & NH & $\mathrm{X}$ & $\mathrm{X}$ & 0.241 & -0.329 & 0.054 & 0.424 \\
\hline Carter $(1998)^{\mathrm{B}}$ & $\mathrm{C}$ & $1890-1995$ & Fennoscandia & -0.075 & 0.047 & 0.132 & -0.509 & 0.423 & 0.933 \\
\hline Schwartz and Chen $(2002)^{\mathrm{A}}$ & $\mathrm{C}$ & 1959-1993 & China & -0.171 & 0.114 & 0.285 & -0.653 & -0.319 & 0.359 \\
\hline Linderholm et al. $(2007)^{\mathrm{A}}$ & $\mathrm{C}$ & $1951-2002$ & Great Baltic Area & -0.126 & 0.026 & 0.148 & -0.263 & 0.189 & 0.456 \\
\hline
\end{tabular}

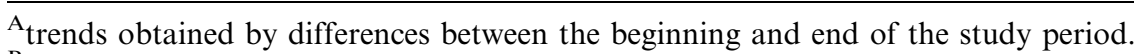

${ }^{B}$ trends obtained by linear regression.

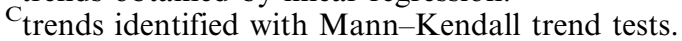

${ }^{1}$ phenological phases identified by setting thresholds to the annual NDVI time series.

${ }^{2}$ phenological phases obtained by identification of the mid-points of the annual NDVI time series.

3 phenological phases obtained by analysis of the rate of change in the annual NDVI time series.

${ }^{4}$ phenological phases identified by spectral or harmonic analysis of the annual NDVI time series.

${ }^{5}$ phenological phases identified by application of a fitting procedure to the annual NDVI time series.

6 phenological phases obtained by fitting the NDVI time-series to accumulated growing degree-days. 
in Lapland. Spring and PDO time series show significant positive correlation, mainly over Asia, but also along the Equator (figure 6(c)). Small patterns of significant negative correlations can be observed in South America and south east Africa. Regarding autumn time series (figure 6(f)), significant negative correlations with PDO index can be observed north of $40^{\circ} \mathrm{N}$, while significant positive correlations are distributed more locally over the rest of the globe. Regarding growing-season time series (figure 6(i)), the distribution of significant correlation is similar to that of autumn time series.

These correlations between climate indices and growing-season parameters show, in general, a good spatial homogeneity: small patches of spatially contiguous pixels exhibit similar correlations, which is opposite to the heterogeneity that can be observed in India or in the Sahara, where correlations do not show spatial coherence. This validates the approach developed above for most of the globe.

\section{Conclusions}

This study presents a method for inferring growing-season parameters (start, end and length) from the whole GIMMS database, including 22 years of NDVI images. This method consists of a yearly fit of the data to a double logistic function, after screening dormancy period (if any) for snow contamination, and the rest of the year for cloud contamination. This method determines the start and end of the growing season, with an uncertainty of 5.5 days, and growing-season length, with an uncertainty of 7.8 days. This approach shows good stability for most of the globe, with the exception of Amazonia, central Africa and south Asia, where enduring cloud cover decreases the accuracy of the fitting procedure, due to an erroneous estimation of dormancy period NDVI values. The trends retrieved from these results are generally in agreement with trends estimated from similar methods used in previous studies. Finally, the correlations between growing-season parameters and climate indices such as SOI, NAO and PDO show some spatial coherence, validating the approach.

The method presented above could be improved by taking into account the inherent variability of certain geographic areas, such as areas with enduring cloud cover, like equatorial or monsoon affected areas, or high interannual NDVI variability, like semi-arid areas. The use of an average year variation of the NDVI over the 22 years of the study for classifying the whole globe could help determine which fitting function (equations (1) and (2), stable or frozen) is more suitable for each pixel. The authors will focus further research in this direction.

More studies are needed to explain the reason behind the retrieved trends, to discriminate between climate and the influence of man. This could be done by carrying out a classification process for each year of the NDVI data, and registering abrupt changes that are not correlated with climate indicators. However, this approach could be hindered by the size pixel of the database, which is too extended to identify local change. Therefore, changes would have to be carried out over large areas $(10 \times 10 \mathrm{~km})$ to be evidenced clearly using this database.

\section{Acknowledgements}

The authors wish to thank the European Union EAGLE project (SST3-CT-2003502057) and the TERMASAT project (Ministerio de Educación y Ciencia, project ESP2005-07724-C05-04) for their financial support. Source for the GIMMS dataset was the Global Land Cover Facility (www.landcover.org). 


\section{References}

Ahas, R., Aasa, A., Menzel, A., Fedotova, V.G. and Scheifinger, H., 2002, Changes in European spring phenology. International Journal of Climatology, 22, pp. 1727-1738.

BADHwar, G.D., 1984, Automatic corn-soybean classification using Landsat MSS data, I, near-harvest crop proportion estimation. Remote Sensing of Environment, 14, pp. $15-29$.

Beaubien, E.G. and Freeland, H.J., 2000, Spring phenology trends in Alberta, Canada: links to ocean temperature. International Journal of Biometeorology, 44, pp. 53-59.

Beck, P., Atzberger, C., Hogda, K.A., Johansen, B. and Skidmore, A., 2006, Improved monitoring of vegetation dynamics at very high latitudes: a new method using MODIS NDVI. Remote Sensing of Environment, 100, pp. 321-334.

CARTER, T.R., 1998, Changes in the thermal growing season in Nordic countries during the past century and prospects for the future. Agricultural and Food Science in Finland, 7, pp. 161-179.

Chen, X., Hu, B. and Yu, R., 2005, Spatial and temporal variation of phenological growing season and climate change impacts in temperate eastern China. Global Change Biology, 11, pp. 1118-1130.

Chmielewski, F.-M. and Rötzer, T., 2002, Annual and spatial variability of the beginning of growing season in Europe in relation to air temperature changes. Climate Research, 19, pp. $257-264$.

De Beurs, K.M. and Henebry, G.M., 2005a, A statistical framework for the analysis of long image time series. International Journal of Remote Sensing, 26, pp. 1551-1573.

De Beurs, K.M. and Henebry, G.M., 2005b, Land surface phenology and temperature variation in the International Geosphere-Biosphere Program high-latitude transects. Global Change Biology, 11, pp. 779-790.

Delbart, N., Kergont, L., Le Toan, T., Lhermitte, J. and Picard, G., 2005, Determination of phenological dates in boreal regions using normalized difference water index. Remote Sensing of Environment, 97, pp. 26-38.

Fischer, A., 1994, A model for the seasonal variations of vegetation indices in coarse resolution data and its inversion to extract crop parameters. Remote Sensing of Environment, 48, pp. 220-230.

Friedl, M., Henebry, G., Reed, B., Huete, A., White, M., Morizette, J., Nemani, R., ZhANG, X. and Myneni, R., 2006, Land Surface Phenology. A community white paper requested by NASA. Available online at: ftp://zeus.geog.umd.edu/Land_ESDR/ Phenology_Friedl_whitepaper.pdf.

HIRSCH, R.M. and SLACK, J.R., 1984, A nonparametric trend test for seasonal data with serial dependence. Water Resources Research, 20, pp. 727-732.

Høgda, K.A., Karlsen, S.R. and Tømmervik, H., 2007, Changes in growing season in Fennoscandia 1982-1999. In Arctic Alpine Ecosystems and People in a Changing Environment, J.B. Ørbæk, R. Kallenborn, I. Tombre, E.N. Hegseth, S. Falk-Petersen and A.H. Hoel (Eds), pp. 71-84 (Berlin, Heidelberg, New York: Springer).

Holben, B.N., 1986, Characteristics of maximum values composite images from temporal AVHRR data. International Journal of Remote Sensing, 7, pp. 1417-1434.

Huete, A.R., Didan, K., Shimabukuro, Y.E., Ratana, P., Saleska, S.R., Hutyra, L.R., YAng, W., Nemani, R.R. and Myneni, R., 2006, Amazon rainforests green-up with sunlight in dry season. Geophysical Research Letters, 33, pp. L06405.

Jonsson, P. and EkLundh, L., 2002, Seasonality extraction by function fitting to time-series of satellite sensor data. IEEE Transactions on Geoscience and Remote Sensing, 40, pp. $1824-1832$.

Julien, Y., Sobrino, J.A. and Verhoef, W., 2006, Changes in land surface temperatures and NDVI values over Europe between 1982 and 1999. Remote Sensing of Environment, 103, pp. 43-55.

Julien, Y. and Sobrino, J.A., 2007, Changes in the global vegetal cover through a phenological analysis of GIMMS data. In IEEE Proceedings of the International 
Workshop on the Analysis of Multi-temporal Remote Sensing Images (MultiTemp). Available at: http://ieeexplore.ieee.org/xpls/abs_all.jsp?arnumber $=4293073$.

Keeling, C.D., Chin, J.F.S. and Whorf, T.P., 1996, Increased activity of northern vegetation inferred from atmospheric CO2 measurements. Nature, 382, pp. 146-149.

Kendall, M.G., 1975, Rank Correlation Methods (London: Charles Griffin).

Linderholm, H.W., Walther, A. and Chen, D., 2008, Twentieth-century trends in the thermal growing-season in the Greater Baltic Area. Climatic Change, 87, pp. 405-419.

LlOYD, D., 1990, A phenological classification of terrestrial vegetation cover using shortwave vegetation index imagery. International Journal of Remote Sensing, 11, pp. 2269-2279.

Los, S.O., 1998, Linkages between global vegetation and climate: an analysis based on NOAA-advanced very high resolution radiometer data. $\mathrm{PhD}$ Thesis, Vrije Universiteit, Amsterdam.

Menzel, A. and Fabian, P., 1999, Growing season extended in Europe. Nature, 397, p. 659.

Moody, A. and Johnson, D.M., 2001, Land-surface phonologies from AVHRR using the discrete Fourier transform. Remote Sensing of Environment, 75, pp. 305-323.

More, J.J., 1977, The Levenberg-Marquardt algorithm: implementation and theory. In Numerical Analysis, G.A. Watson (Ed.), Lecture Notes in Mathematics, 630, SpringerVerlag.

Moulin, S., Kergoat, L., Viovy, N. and Dedieu, G., 1997, Global scale assessment of vegetation phenology using NOAA/AVHRR satellite measurements. Journal of Climate, 10, pp. 1154-1170.

Myneni, R.B., Keeling, C.D., Tucker, C.J., Asrar, G. and Nemani, R.R., 1997, Increased plant growth in the northern high latitudes from 1981 to 1991. Nature, 386, pp. 698-702.

Osborne, C.P., Chuine, I., Viner, D. and Woodward, F.I., 2000, Olive phenology as a sensitive indicator of future climatic warming in the Mediterranean. Plant, Cell and Environment, 23, pp. 701-710.

Piao, S., Fang, J., Zhou, L., Ciais, P. and Zhu, B., 2006, Variations in satellite-derived phenology in China's temperate vegetation. Global Change Biology, 12, pp. 672-685.

PINZON, J., 2002, Using HHT to successfully uncouple seasonal and interannual components in remotely sensed data. In SCI 2002 Conference Proceedings, 14-18 July, Orlando, Florida.

Pinzon, J., Brown, M.E. and Tucker, C.J., 2004, Satellite time series correction of orbital drift artifacts using empirical mode decomposition. In EMD and its Applications, N.E. Huang and S.S.P. Shen (Eds), 10, pp. 285-295 (Singapore: World Scientific).

Price, J.C., 1991, Timing of NOAA afternoon passes. International Journal of Remote Sensing, 12, pp. 193-198.

Reed, B.C., Brown, J.F., Vanderzee, D., Loveland, T.R., Merchant, J.W. and OHLEN, D.O., 1994, Measuring phenological variability from satellite imagery. Journal of Vegetation Science, 5, pp. 703-714.

Rouse, J.W., HaAs, R.H., Schell, J.A. and Deering, D.W., 1973, Monitoring vegetation systems in the Great Plains with ERTS. In Third ERTS Symposium, NASA SP-351 I, pp. 309-317.

Sakamoto, T., Yokosawa, M., Toritani, H., Shibayama, M., Ishitsuka, N. and Ohno, H., 2005, A crop phenology detection method using time-series MODIS data. Remote Sensing of Environment, 96, pp. 366-374.

SALINGER, M.J., 2005, Climate variability and change: past, present and future - an overview. Climatic Change, 70, pp. 9-29.

Schwartz, M.D., 1992, Phenology and springtime surface layer change. Monthly Weather Review, 120, pp. 2570-2578.

Schwartz, M.D. and Chen, X., 2002, Examining the onset of spring in China. Climate Research, 21, pp. 157-164.

Schwartz, M.D., Ahas, R. and Aasa, A., 2006, Onset of spring starting earlier across the northern hemisphere. Global Change Biology, 12, pp. 343-351. 
Sellers, P.J., Los, S.O., Tucker, C.J., Justice, C.O., Dazlich, D.A., Collatz, G.J. and RANDALL, D.A., 1996, A revised land surface parametrization (SiB2) for atmospheric GCMs. Part 2: the generation of global fields of terrestrial biophysical parameters from satellite data. Journal of Climate, 9, pp. 706-737.

Shabanov, N.V., Zhou, L.M., Knyazikhin, Y., Myneni, R.B. and Tucker, C.J., 2002, Analysis of interannual changes in northern vegetation activity observed in AVHRR data from 1981 to 1994. IEEE Transactions on Geoscience and Remote Sensing, 40, pp. 115-130.

Smith, P.M., Kalluri, S.N.V., Prince, S.D. and Defries, R., 1997, The NOAA/NASA pathfinder AVHRR 8-km land data set. Photogrammetric Engineering and Remote Sensing, 63, p. 12.

StÖCKli, R. and Vidale, P.L., 2004, European plant phenology and climate as seen in a 20year AVHRR land-surface parameter dataset. International Journal of Remote Sensing, 25, pp. 3303-3330.

Tao, F., Yokozawa, M., Xu, Y., Hayashi, Y. and Zhang, Z., 2006, Climate changes and trends in phenology and yields of field crops in China 1981-2000. Agricultural and Forest Meteorology, 138, pp. 82-92.

TAteishi, R. and EBATA, M., 2004, Analysis of phenological change patterns using 1982-2000 advanced very high resolution radiometer (AVHRR) data. International Journal of Remote Sensing, 25, pp. 2287-2300.

Tucker, C.J., Slayback, D.A., Pinzon, J.E., Los, S.O., Myneni, R.B. and Taylor, M.G., 2001, Higher northern latitude NDVI and growing season trends from 1982 to 1999. International Journal of Biometeorology, 45, pp. 184-190.

Tucker, C.J., Pinzon, J.E., Brown, M.E., Slayback, D., Pak, E.W., Mahoney, R., Vermote, E. and El Saleous, N., 2005, An extended AVHRR 8-km NDVI data set compatible with MODIS and SPOT vegetation NDVI data. International Journal of Remote Sensing, 26, pp. 4485-4498.

White, M.A. and Nemani, R.R., 2006, Real-time monitoring and short-term forecasting of land surface phenology. Remote Sensing of Environment, 104, pp. 43-49.

White, M.A., Thornton, P.E. and Running, S.W., 1997, A continental phenology model for monitoring vegetation responses to interannual climatic variability. Global Biogeochemical Cycles, 11, pp. 217-234.

Wolfe, D.W., Schwartz, M.D., Lakso, A.N., Otsuki, Y., Pool, R.M. and Shaulis, N.J., 2005, Climate change and shifts in phenology of three horticultural woody perennials in northeastern USA. International Journal of Biometeorology, 49, pp. 303-309.

Zhang, X., Friedl, M.A., SchaAf, C.B. and Strahler, A.H., 2004, Climate controls on vegetation phenological patterns in northern mid- and high latitudes inferred from MODIS data. Global Change Biology, 10, pp. 1133-1145.

Zhou, L., Tucker, C.J., Kaufmann, R.K., Slayback, D., Shabanov, N.V. and MYNENI, R.B., 2001, Variations in northern vegetation activity inferred from satellite data of vegetation index during 1981 to 1999. Journal of Geophysical Research, 106, pp. 20069-20083.

Zhou, L., Kaufmann, R.K., Tian, Y., Myneni, R.B. and Tucker, C.J., 2003, Relation between interannual variations in satellite measures of northern forest greenness and climate between 1982 and 1999. Journal of Geophysical Research, 108, p. 4004. 